\title{
Influence of Borosilicate Addition on Mechanical Properties and Sinterability of $8 \mathrm{YSZ}$
}

\begin{abstract}
B. AKTAS*
Harran University, Engineering Faculty, Department of Mechanical Engineering, 63300, Sanliurfa, Turkey

The influence of borosilicate (BS) addition on the mechanical properties and sinterability of yttria-stabilized zirconia (8YSZ) was investigated using scanning electron microscopy (SEM) and Vickers-hardness test. Undoped and $0.5-10 \mathrm{wt} . \%$ BS-doped 8 YSZ powders were prepared using a colloidal process. The powders were then pelletized under a pressure of $200 \mathrm{MPa}$. The BS-doped $8 \mathrm{YSZ}$ specimens were sintered at $1200-1400^{\circ} \mathrm{C}$ for $1 \mathrm{~h}$. SEM results showed that intergranular glass phases were formed at the grain boundaries of $8 \mathrm{YSZ}$, particularly in the 5 and $10 \mathrm{wt} . \%$ BS-doped 8 YSZ specimens. These intergranular glass phases caused a decrease in grain size of 8YSZ. The grain sizes of the undoped and $0.5 \mathrm{wt} \%$ BS-doped $8 \mathrm{YSZ}$ specimens were $2.68 \mu \mathrm{m}$ and $1.83 \mu \mathrm{m}$, respectively. The addition of BS to $8 \mathrm{YSZ}$ caused a decrease in the relative density. In addition, the relative density was found to be increased with higher sintering temperature. The hardness of 8YSZ decreased with the increase in BS dopant amount, due to presence at the grain boundaries of a BS glassy phase that has a lower hardness than 8YSZ.
\end{abstract}

DOI: 10.12693/APhysPolA.129.677

PACS/topics: 81.05.Je, 81.40.Np, 82.47.Ed

\section{Introduction}

Grain growth occurs in ceramic materials during sintering and annealing at high temperatures. The mechanical properties of coarse-grained ceramic materials are inferior to those of the fine-grained ones. Many methods have been developed to prevent the grain coarsening and to make the structure stable during the sintering and heat treatment at high temperatures. These methods include making composite ceramics, using additives that facilitate sintering (liquid phase sintering), and cold and hot isostatic pressing processes [1].

8 mol.\% yttria-stabilized cubic zirconia (8YSZ) has a wide range of applications in many areas, such as aerospace, automotive industry, healthcare, manufacture of high-temperature turbine blades, and solid electrolytes. Because 8YSZ has high oxygen ionic conductivity in a wide temperature range and oxygen partial pressure, it is often used as a solid electrolyte in solid oxide fuel cells (SOFCs) [2-7]. For these applications, 8YSZ should have high ionic conductivity, high strength, and considerable chemical and electrical stability. The fact that it has low mechanical strength at high temperatures limits the use of 8YSZ as a solid electrolyte. Due to excessive grain growth at high temperatures and long-term working conditions, the mechanical strength of the electrolyte material decreases, making the fuel cell unworkable [8].

As mentioned above, 8YSZ exhibits low mechanical strength, due to the grain growth at high operating temperature in the SOFCs. The prevention of grain growth in $8 \mathrm{YSZ}$ is important in order to improve its

*e-mail: baktas@harran.edu.tr mechanical properties. In this study, the influence of borosilicate (BS) addition on the sinterability and mechanical properties of 8 YSZ is investigated using Vickers hardness test and scanning electron microscopy (SEM).

\section{Materials and procedure}

8YSZ powder (Tosoh, Japan) was used as the matrix material, and the BS powder (Specialty Glass, Florida), up to 10 wt.\% was used as dopant. The average grain sizes of the powders were 0.3 and $0.25 \mu \mathrm{m}$ for $8 \mathrm{YSZ}$ and $\mathrm{BS}$, respectively.

The specimens used for the microstructural and mechanical investigations were prepared by colloidal processing. Doping was carried out in a plastic container by mechanically mixing up to 10 wt.\% of BS with 8 YSZ using zirconia balls and ethanol. Mechanical mixing was performed in a "speks" type mixer at $200 \mathrm{rpm}$ for $12 \mathrm{~h}$. Following mixing, the container lid was removed, and the prepared slurry was left in air for drying during $24 \mathrm{~h}$. After drying, the agglomerated powders were ball milled for $10 \mathrm{~min}$ to achieve a uniform dispersion. The powders were then passed through a $60 \mu \mathrm{m}$ sieve and pressed at $200 \mathrm{MPa}$ in a single-axis die with a radius of $10 \mathrm{~mm}$ and a height of $4 \mathrm{~mm}$. The inner surface of the steel die was cleaned after each dry pressing, and stearic acid was applied to its side walls. Sintering was carried out in a box-type furnace under atmospheric pressure. The pressed pellets were pre-sintered at $1000^{\circ} \mathrm{C}$ and then sintered at $1200-1400^{\circ} \mathrm{C}$ for $1 \mathrm{~h}$. The surfaces of the sintered specimens were ground and polished using metallographic method after the sintering process, and then thermally etched at $1350{ }^{\circ} \mathrm{C}$ for $1 \mathrm{~h}$. Microstructural investigations of the sintered specimens were performed using a scanning electron microscope (SEM, JEOL LV 6060). The grain sizes of the specimens were measured using a mean linear intercept method. 
The average grain sizes of the specimens were determined with the following equation:

$$
D=\frac{L_{i}}{N_{i} M},
$$

where $L_{i}$ is the length of the line, $N_{i}$ is the number of grain-boundary intercepts, and $M$ is the magnification in the photomicrograph of the material.

Both the hardness and fracture toughness of the specimens were determined using a Vickers hardness tester with a load of $2 \mathrm{~kg}$ and duration of $15 \mathrm{~s}$. Hardness values were calculated using the following equation:

$$
H_{v}=\frac{1854 P}{d^{2}},
$$

where $P$ is the applied load, and $d$ is the mean value of the diagonal length.

\section{Results and discussion}

The microstructures of specimens doped with various amounts of BS after sintering at $1400^{\circ} \mathrm{C}$ for $1 \mathrm{~h}$ are presented in Fig. 1. As can be observed from the figures, the undoped $8 \mathrm{YSZ}$ shows coarse and co-axial polygonal grains (Fig. 1a). However, BS-doped 8YSZ specimens show smaller grains (Fig. 1b-e). The SEM images

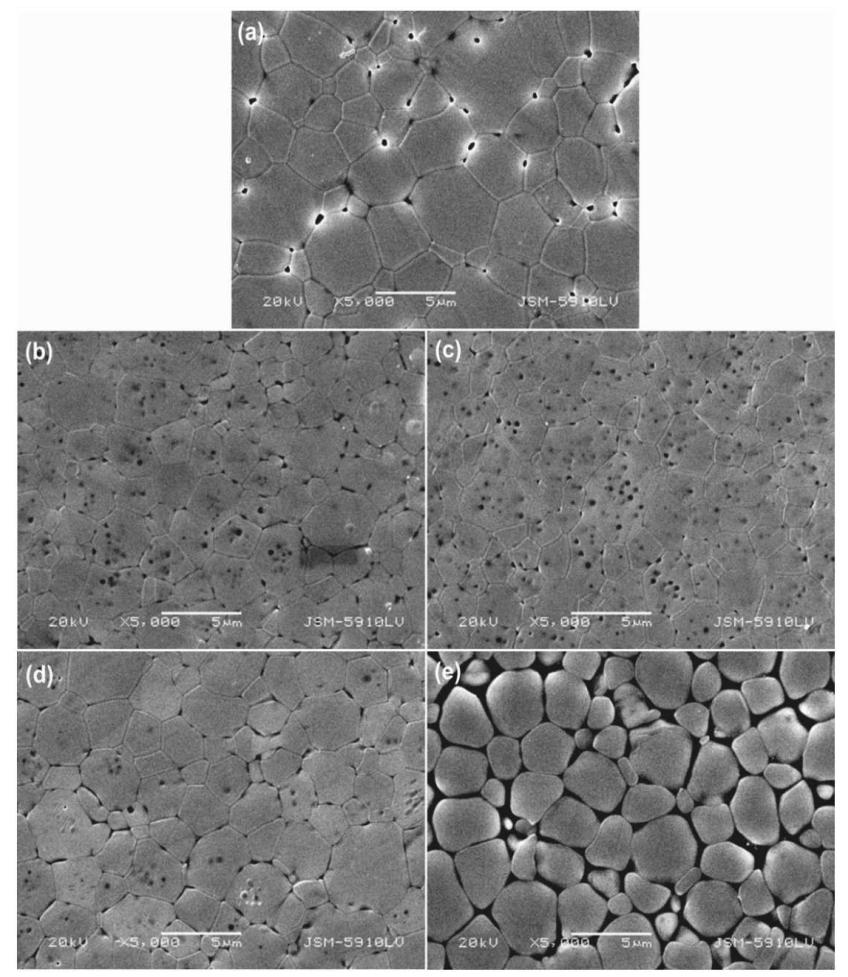

Fig. 1. Microstructures of undoped and BS-doped $8 \mathrm{YSZ}$ specimens sintered at $1400^{\circ} \mathrm{C}$ for $1 \mathrm{~h}$ : (a) Undoped 8YSZ, (b) 0.5 wt.\% BS-doped 8YSZ, (c) 1 wt.\% BS-doped 8YSZ, (d) 5 wt.\% BS-doped 8YSZ, and (e) 10 wt.\% BS-doped 8YSZ.

(Fig. 1d-e) and the energy-dispersive X-ray spectroscopy (EDS) results of the 5 and 10 wt.\% BS-doped 8 YSZ samples show thin glassy phases at the grain boundaries.
The presence of the BS glassy phases at the triple junction of intersecting grain boundaries led to conversion to spherical grains from co-axial polygonal grains. As the $\mathrm{BS}$ addition is increased, an increase in thickness of the BS glassy phase layer is observed (Fig. 1d-e).

Figure 2 shows the relationship between the addition of BS and the relative densities of the resulting materials at different temperatures. A relative density of $93 \%$ was reached at $1400^{\circ} \mathrm{C}$ in the undoped $8 \mathrm{YSZ}$, while the relative densities of $0.5,1,5$, and 10 wt. $\%$ BS-doped $8 \mathrm{YSZ}$ specimens were $87 \%, 91 \%, 82 \%$ and $88 \%$, respectively. As a result, the BS addition to $8 \mathrm{YSZ}$ caused a decrease in the relative density, due to presence of the glassy phase layers at the grain boundaries.

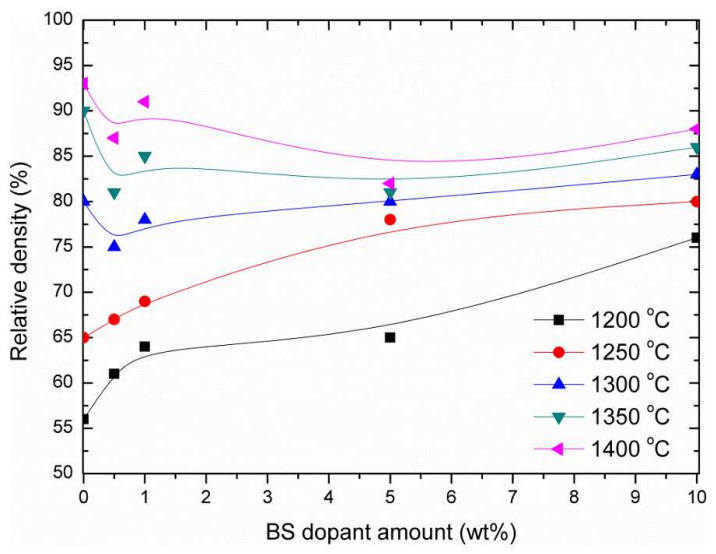

Fig. 2. Relative densities of undoped and BS-doped 8YSZ specimens sintered at various temperatures for $1 \mathrm{~h}$.

As BS amount was increased, it has segregated as the second phase (glassy phase) at the grain boundaries of 8YSZ, leading to an increase in thickness of the glassy layer. This BS glassy phase layer caused loss of contact between the grains of $8 \mathrm{YSZ}$, and a decrease in diffusivity of grain boundary. As is known, the grain boundary diffusion is a powerful agent transport mechanism. The BS glassy layers in the grain boundaries lead to longer grain boundary diffusion paths, and therefore slowed down the diffusion of the atoms along the grain boundaries between the BS glassy phase layers and 8YSZ. Furthermore, another reason for the decrease in densities may be caused by the smaller density of the BS $\left(2.2 \mathrm{~g} / \mathrm{cm}^{3}\right)$ compared to 8 YSZ $\left(5.95 \mathrm{~g} / \mathrm{cm}^{3}\right)$.

Figure 3 shows how grain size of $8 \mathrm{YSZ}$ changes with BS content. From this figure, it can be observed that the average grain size decreases with the BS content. The grain size of BS-doped 8YSZ samples decreases, due to the presence of the glassy phase at the grain boundaries of $8 \mathrm{YSZ}$. This BS glassy phase with high viscosity at the grain boundaries causes a decrease in the grain boundary diffusion of $8 Y$ YSZ. Due to the slow diffusion at the grain boundaries in the BS-doped 8YSZ samples, the grain size is decreased. Intergranular and grain boundary phases with high solubility are known to have low 
viscosity and high diffusion rate at high temperatures. BS is known to have a high viscosity because it contains $\mathrm{B}^{3+}$ ions network formation. As a result, it is expected to have a low diffusion rate [9].

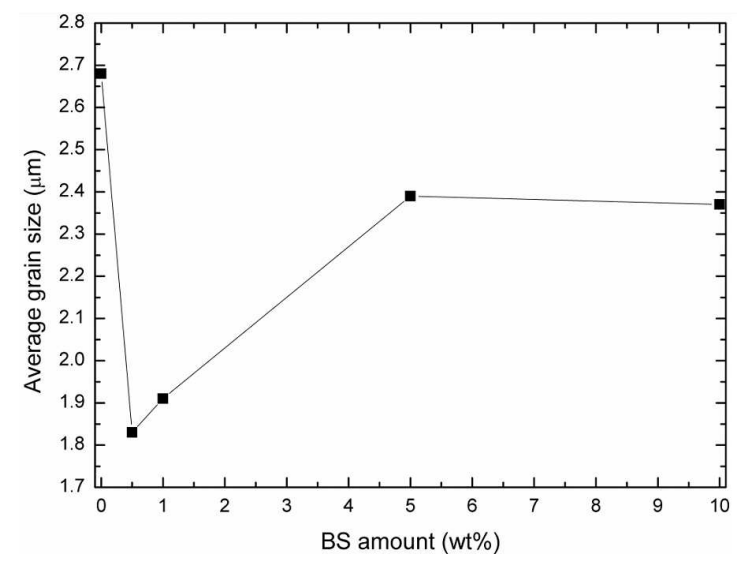

Fig. 3. Plot of grain size versus BS content of doped and undoped $8 \mathrm{YSZ}$ specimens after sintering at $1400^{\circ} \mathrm{C}$ for $1 \mathrm{~h}$.

The results of Vickers hardness tests of the undoped and BS-doped 8YSZ samples sintered at $1400^{\circ} \mathrm{C}$ for $1 \mathrm{~h}$ are presented in Fig. 4. The hardness of the undoped, and $0.5,1,5$, and 10 wt.\% BS-doped 8YSZ samples is $12.35,13.17,11.04,5.64$, and $8.53 \mathrm{GPa}$, respectively.

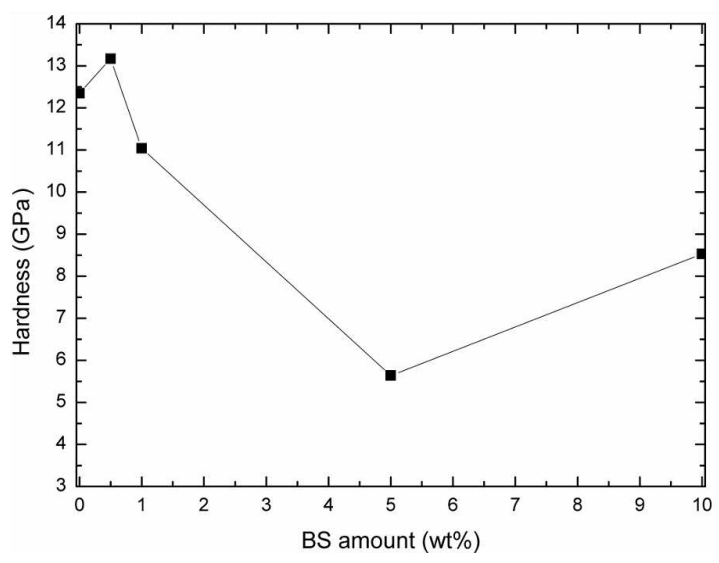

Fig. 4. Effects of BS content on the hardness of 8YSZ samples sintered at $1400^{\circ} \mathrm{C}$ for $1 \mathrm{~h}$.

In general, the addition of BS to 8YSZ has led to a decrease in hardness. The reason for this decrease may be the low hardness of the BS glassy phase. The hardness of ceramics is usually affected by the intrinsic deformability of the ceramic and microstructural features, such as multiphases, grain size and orientation, porosity, and grain boundary constitution [10].

\section{Conclusions}

BS additive has precipitated as a glassy phase around the grains and grain boundaries of 8YSZ. The thickness of glassy phase layer at the grain boundaries has increased with the increase of the BS additive amount. This glassy phase causes slow diffusion of grain boundaries, resulting in a reduction in grain size. The addition of BS to 8 YSZ leads to a decrease in the relative density. The relative density also increases with the sintering temperature. The hardness of 8YSZ has decreased with BS addition, due to the existence of the glassy phase.

\section{Acknowledgments}

This work has been supported by HUBAK (the scientific research projects commission of Harran University, Sanliurfa, TURKEY) under project number K15007. The author is grateful to the scientific research projects commission of Harran University for financial support.

\section{References}

[1] S. Tekeli, T. Boyacıŏlu, A. Güral, Ceram. Int. 34, 1959 (2008).

[2] F.F. Lange, Fracture Mechanics of Ceramics, Vol. 1, Plenum, New York 1978, p. 3.

[3] C.A. Anderson, T.K. Gupta, Science and Technology of Zirconia, Advances in Ceramics, Vol. 3, The American Ceramic Society, Columbus, OH 1981, p. 184.

[4] N. Claussen, M. Ruehle, Science and Technology of Zirconia, Advances in Ceramics, Vol. 3, The American Ceramic Society, Columbus, OH 1981, p. 137.

[5] C.T. Grain, J. Am. Ceram. Soc. 50, 288 (1967).

[6] M.G. Scott, J. Mat. Sci. 10, 1527 (1975).

[7] J.M. Marder, T.E. Mitchell, A.H. Heuer, Acta Metall. 31, 387 (1983).

[8] T. Zhang, Z. Zeng, H. Huang, P. Hing, J. Kilner, Mater. Let. 57, 124 (2002).

[9] A.A. Sharif, P.H. Imamura, T.E. Mitchell, M.L. Mecartney, Acta Mater. 46, 3863 (1998).

[10] W.E. Lee, W.M. Rainforth, Ceramic Microstructures: Property Control by Processing, Chapman and Hall, London 1994, p. 255. 